\begin{tabular}{l} 
Observatório de \\
Inovação do Turismo \\
Revista Acadêmica \\
ISSN 1980-6965 \\
www.ebape.fgy.br/revistaoit \\
\hline
\end{tabular}

\title{
Roteiro Integrado da Civilização do Açúcar: algumas considerações sobre o processo de planejamento e desenvolvimento do turismo no estado de Alagoas
}

Integrated Routes of Sugar Civilization: remarks on the process of planning and development of tourism in the state of Alagoas

Silvana Pirillo Ramos

Levy Felix Ribeiro

\section{Resumo}

No Programa de Regionalização do Turismo - Roteiros do Brasil, por meio do Projeto Rede de Cooperação Técnica, desenvolvem-se roteiros turísticos em diferentes regiões do País, que viabilizam a interiorização do turismo e um novo modelo para essa atividade econômica que atenda às novas tendências de mercado. O roteiro proposto para a região nordeste do País é o Roteiro Integrado da Civilização do Açúcar (RICA) que integra os estados de Pernambuco, Alagoas e Paraíba em uma proposta de trabalho centrada na herança cultural açucareira: os engenhos, a cachaça, o melaço, o artesanato e a gastronomia. Observado esse escopo, neste artigo, analisam-se o processo de planejamento e de desenvolvimento do RICA, no estado de Alagoas, por meio de documentos e entrevistas com gestores de turismo dos municípios envolvidos, a fim de identifi-

Artigo recebido em 20 de Abril de 2014 e aceito em 10 de Julho de 2014. 
car as falhas no processo de planejamento e de desenvolvimento do Roteiro. Como resultado, apresenta-se o levantamento de fatores impeditivos do desenvolvimento do RICA; entre eles, a dificuldade de consolidação do grupo gestor e de efetivação do planejamento participativo. Trata-se de uma reflexão sobre as peculiaridades da atividade econômica do turismo no espaço e a necessidade de uma metodologia de planejamento que identifique estruturas de poder e possa garantir a efetividade das instâncias de participação.

Palavras-chave: Roteiro Integrado da Civilização do Açúcar, planejamento de roteiros turísticos, políticas de turismo, Programa de Regionalização do Turismo

\section{Abstract:}

The Program for Tourism Regionalization - Routes of Brazil, through the Network Technical Cooperation Project aims at developing tourist routes in different regions of the country, enabling the internalization of tourism and a new model for economic activity that meets new market trend. The route proposed for the northeast region of the country is the Integrated Route of Sugar Civilization (IRSC), which includes the states of Pernambuco, Paraiba and Alagoas in a work proposal on the cultural heritage of the sugar culture: sugar mills, cachaça, molasses, crafts and cuisine. The paper analyzes the process of planning and IRSC development in Alagoas State by means of documents and interviews with tourism managers of the municipalities involved in order to identify gaps in the planning process and route development. As a result, it presents a survey of factors that prevent the IRSC development, including the difficulty of consolidating the management group and participatory planning. This is a reflection on the peculiarities of tourism economic activity in space and the need for a planning methodology that identifies structures of power and can ensure the effectiveness of instances of participation. 
Key words: Integrated Route of Sugar Civilization, planning for tourist routes, tourism policies, Program for Regionalization of Tourism

\section{Apresentação}

Em 2004, no Ministério do Turismo, inicia-se o Programa de Regionalização do Turismo - Roteiros do Brasil em que, por meio do planejamento estratégico, visa-se promover as transformações regionais no turismo, viabilizando roteiros integrados entre municípios e regiões contíguas do País, propondo-se um aproveitamento, de forma sustentável, do potencial turístico de cada localidade. Para tanto, desenvolve-se o projeto Rede de Cooperação Técnica para Roteirização, com a proposta de cinco roteiros em diferentes regiões brasileiras; a primeira edição é de 2005, e a segunda, de 2008.

Na proposta para a região nordeste, no projeto da segunda edição da Rede de Cooperação Técnica, em 2008, desenvolve-se o Roteiro Integrado da Civilização do Açúcar - RICA, cuja área de abrangência totaliza 21 municípios distribuídos em três estados: Alagoas (Maceió, Rio Largo, União dos Palmares, Maragogi, Pilar, Marechal Deodoro e Coruripe), Paraíba (João Pessoa, Alagoa Nova, Alagoa Grande, Areia, Bananeiras, Serraria) e Pernambuco (Recife, Olinda, Ipojuca, Goiânia, Vicência, Nazaré da Mata, Igarassu, Itamaracá). No Roteiro, apresenta-se como eixo temático o modo de vida, os saberes e os fazeres entremeados na cultura da cana-de-açúcar, no período colonial. Vale lembrar que a cana-de-açúcar representa a base histórico-econômica sobre a qual foi construída a cultura característica da região, estruturada em relações entre portugueses, holandeses, negros e índios. O engenho de açúcar compunha-se de casa-grande, senzala, capela, horta e canavial onde se utilizava da mão de obra escrava africana e a produção de açúcar destinava-se à metrópole portuguesa e ao mercado europeu. 
No Manual de Orientações Metodológicas para a Rede de Cooperação Técnica para a Roteirização, elencam-se os principais atrativos das cidades históricas que compõem o roteiro: arquitetura colonial (casarios, igrejas, fortes), visitação a engenhos, hospedagem nas casas-grandes dos antigos engenhos, interação com os costumes da população local, encenação de fatos históricos, culinária típica (rapadura, cachaça), folclore (maracatu, frevo, ciranda), praias de águas calmas (coqueiros, piscinas naturais, recifes e bancos de areia) e reservas florestais. Destacam-se, ainda, como atrativos turísticos, as comunidades quilombolas, a gastronomia e o artesanato (IMB, 2008).

O Roteiro é uma proposta de trabalho com a herança cultural advinda da cultura açucareira e das relações sociais engendradas, com base no desenvolvimento, em que se requer um trabalho de estruturação como um itinerário cultural, demandando um amplo inventário dos patrimônios material e imaterial da região, fundamentado numa contextualização sócio-histórica que permita a compreensão e a interpretação dos saberes e fazeres do local.

O RICA compõe-se da proposta de vivência de três fases distintas pelo turista - a da contextualização da Civilização do Açúcar em Pernambuco vivida nos atrativos culturais, o fabrico de cachaça e rapadura nos engenhos da Paraíba, e a industrialização do açúcar e álcool em Alagoas, recheado de experiências nos segmentos turísticos prioritários - cultura, rural, ecoturismo, aventura, sol e praia (IMB, 2008, p. 45).

O segmento-âncora do RICA, em conformidade com as vocações do território, é o turismo cultural, definido pelo Ministério do Turismo como "aquele que compreende as atividades turísticas relacionadas com a vivência do conjunto de elementos significativos do patrimônio histórico-cultural e dos eventos culturais, valorizando e promovendo os bens materiais e imateriais da cultura" (BRASIL, 2012); porém a proposta é explorar outros segmentos de forma complementar, como turismo de sol e praia, ecoturismo, turismo de aventura e turismo rural. 
Ressalte-se que é um grande desafio introduzir o turismo cultural como segmento- âncora em território cujo modelo vigente é o de turismo de sol e praia. A proposta é a quebra de um paradigma consolidado e a transformação de uma imagem solidamente construída da região nos cenários nacional e internacional.

A interiorização do turismo e a proposta de um novo modelo para essa atividade econômica vêm ao encontro da meta do Ministério do Turismo de promover a inclusão social, permitindo um trabalho com a inserção da população local na atividade econômica do turismo e a melhoria de suas condições de vida. O modelo de gestão adotado pelo Ministério do Turismo está voltado para o interior dos municípios do Brasil, para as riquezas ambientais, materiais e patrimoniais, e para as populações, em contraponto aos prejuízos impostos pela modernização. Esse propósito pode ser alcançado pela gestão compartilhada e pelo planejamento nacional construído com base em especificidades locais (BRASIL, 2004, p. 8).

Por outro lado, mesmo com toda a potencialidade para o desenvolvimento, o RICA, desde 2008, vem tentando sem sucesso consolidar-se como um produto turístico na região, mas são inúmeros os empecilhos que podem ser elencados para justificar a extrema dificuldade em sua operacionalização.

Nesse cenário, por meio deste artigo, objetiva-se fazer uma análise das dificuldades para o planejamento e o desenvolvimento do Roteiro, das metodologias utilizadas e das falhas nas diferentes etapas propostas pelo Programa. Para tanto, utilizou-se um estudo de caso $^{1}$ delimitando-se a área de pesquisa ao estado de Alagoas. Fizeram-se análises documentais de programas,

\footnotetext{
${ }^{1}$ Estudo de caso se caracteriza, nesse contexto, por constituir-se na investigação de um único caso em profundidade. O ponto de partida dessa modalidade de pesquisa consiste na identificação da unidade de investigação, sobre a qual são coletados os dados com a intenção de estabelecer generalizações válidas para a população que ela representa. Pretende-se, assim, ao abstrair características individuais e particulares dos objetos de pesquisa, chegar a verdades gerais que são válidas para todos os indivíduos (GONÇALVES, 2006, p. 20).
} 
planos e projetos que geraram o RICA, e visitas in loco em cada um dos municípios alagoanos inseridos na proposta e, por meio de roteiro semiestruturado, entrevistaram-se gestores de turismo de quatro municípios alagoanos inseridos no Roteiro ${ }^{2}$ a fim de verificar de que forma se incluíram no processo de planejamento e desenvolvimento do RICA, a atuação no grupo gestor, as dificuldades enfrentadas, os aspectos positivos e negativos do referido processo e as considerações sobre os motivos do fracasso do Roteiro no estado de Alagoas.

A "falência" do planejamento e a frustração de um projeto político para o desenvolvimento do turismo justificam a necessidade de uma análise das etapas que foram propostas e desenvolvidas a fim de elaborar subsídios capazes de possibilitar um repensar sobre as metodologias utilizadas para a construção de produtos turísticos e sobre as estratégias utilizadas para a efetivação das políticas de turismo no País.

\section{Projeto Rede de Cooperação Técnica para Roteirização}

Nas Diretrizes Operacionais do Programa de Regionalização do Turismo - Roteiros do Brasil, apresentam-se metas para melhoria da qualidade do produto turístico e a diversificação da oferta, e sugerem-se, para atingi-las, a estruturação de destinos, a ampliação e a qualificação de mercados turísticos, o aumento da inserção competitiva do produto turístico no mercado internacional, o crescimento do consumo do produto turístico no mercado nacional, da taxa de permanência e do gasto médio do turista (BRASIL, 2008a). Regionalizar, nesse contexto, tem um sentido maior do que a simples aproximação dos municípios por semelhança; o que se propõe é uma aproximação pautada pela capacidade

\footnotetext{
${ }^{2}$ Os gestores entrevistados foram secretários e/ou diretores de turismo dos municípios de Maragogi, Coruripe, Maceió e União dos Palmares. A identidade dos gestores foi mantida em sigilo por questões políticas.
} 
de cooperação e pela identificação entre os envolvidos no processo, visando à sinergia entre o Poder Público, a iniciativa privada, o Terceiro Setor e a comunidade.

Para o Ministério do Turismo,

busca-se reafirmar as formas de existência das comunidades, seus costumes e suas crenças, as relações de poder e de interesse que as unem e as distanciam. Enfim, trata-se de uma contribuição para superar obstáculo e divergências e pensar a geração de riquezas vinculada ao movimento de grupos sociais regionalmente organizados, que demandam espaço de participação no processo de decisão e gestão (BRASIL, 2004, p. 8).

O Programa de Regionalização do Turismo contrapõe-se ao que o Ministério do Turismo define como "modelo concentrado do turismo" que não valoriza o local e contraria as principais tendências do mercado turístico mundial, caracterizadas por um turista em busca de vivências e experiências, pela personalização dos pacotes turísticos e pela segmentação do mercado.

As políticas voltadas à promoção do turismo - calcada em pacotes pré-formatados, em fretamentos aéreos e em estruturas hoteleiras de grande porte, principalmente resorts, que, naturalmente, favorece somente a grandes corporações privadas, como cadeias hoteleiras, transportadoras aéreas e grandes operadoras turísticas - constituem modelo concentrador de renda cujos impactos sociais e ambientais, avaliados pelo custo total, terminam sendo negativos. A renda gerada pelo turismo é geralmente, apropriada pelos grandes centros que exportam seus produtos e serviços para os destinos turísticos, enquanto são nesses que os principais impactos sociais e ambientais ocorrem (Brasil, 2005, p. 23).

Para o Ministério do Turismo, o processo de roteirização tem, como principal objetivo, a estruturação, a qualificação e a ampliação, de forma integrada e organizada, da oferta de produtos turísticos. Entre as estratégias do Programa, está a formatação de roteiros turísticos, integrando municípios e estados contíguos e podendo perpassar por uma ou várias regiões, sempre 
estruturados em torno de propostas temáticas. Roteiro turístico caracteriza-se como um itinerário constituído por um ou mais elementos que lhe confere identidade, definido e estruturado para fins de planejamento, gestão, promoção e comercialização turística (FREIRE, 2007).

Para que os objetivos possam ser alcançados, no Programa de Regionalização do Turismo - Roteiros do Brasil, estabelece-se metodologia para seu desenvolvimento, tendo como princípio básico norteador o envolvimento e a participação da comunidade local na estruturação do Roteiro, configurando uma proposta de fomento ao desenvolvimento endógeno.

É importante destacar que o desenvolvimento endógeno é localmente determinado, tende a manter os benefícios do desenvolvimento na economia local, respeitando os valores da população, enquanto o desenvolvimento exógeno é enxertado no local e é externamente determinado, tende a exportar os produtos para fora das regiões e, geralmente, não valoriza e não respeita as peculiaridades da cultura local (SLEE, 1994). Ao pensar em desenvolvimento endógeno, no Ministério do Turismo, parte-se de um modelo de turismo diferenciado do predominante até o momento no Brasil: o de sol e praia modalidade do turismo de massa. Esse novo modelo de turismo vem ao encontro de uma macrotendência da atividade econômica na qual se aponta a emergência de um novo consumidor: um tipo de turista que está em busca de diferenciais, de valorização das características peculiares dos locais visitados, que se interessa mais em interagir com a comunidade local e, consequentemente, promove um turismo que pode gerar mais impactos positivos, distanciando-se do modelo centralizador.

Dessa forma, iniciou-se, em janeiro de 2005, o Projeto Rede de Cooperação Técnica para Roteirização, coordenado pelo Ministério do Turismo (MTur) e o Serviço Brasileiro de Apoio às Micro e Pequenas Empresas (SEBRAE), assentado no Serviço Nacional de Aprendizagem Comercial (SENAC) e na 
Associação Brasileira das Operadoras de Turismo (BRAZTOA) e com gestão do Instituto Marca Brasil (IMB), tendo como estratégia a formação de roteiros integrados entre as regiões do País, criando novos produtos turísticos ou qualificando os já existentes e trabalhando a inserção de roteiros nos mercados nacional e internacional.

Conforme o Manual da Rede de Cooperação Técnica para a Roteirização (BRASIL, 2010), a palavra-chave para o processo de roteirização é "sinergia" sinergia entre os setores públicos e privados, entre os territórios, entre os atrativos, entre os elementos da cadeia produtiva do turismo e outras atividades econômicas desenvolvidas na região -, o que leva à formação da chamada "rede de cooperação".

No processo de roteirização, a rede de cooperação permite, em suma, que representantes de órgãos públicos, instituições privadas e entidades afins estabeleçam laços de colaboração e comprometimento, compartilhem de conhecimentos necessários para o acompanhamento, a estruturação, a avaliação e o gerenciamento dos roteiros turísticos, oportunizando, assim, uma vasta troca de experiências e, por conseguinte, fomentando o crescimento individual e coletivo (BRASIL, 2010, p.74).

No Projeto Rede de Cooperação Técnica para Roteirização, cuja primeira edição foi em 2005, envolveram-se 130 técnicos de todas as regiões brasileiras que, com base em propostas de metodologias adaptadas às especificidades de cada região, estruturaram cinco roteiros: Rota das Emoções - JericoacoaraDelta do Parnaíba-Lençóis Maranhenses, Roteiro Turístico Caminhos da Revolução Acreana, Roteiro Integrado Iguassu-Misiones, Roteiro Integrado Estrada Real-Caminho Velho e Roteiro Integrado de Brasília-Chapada dos Veadeiros.

Na segunda edição do Projeto, iniciada em 2008, com base na avaliação das experiências obtidas na primeira edição, o diferencial foi a adoção de uma 
única metodologia de planejamento e desenvolvimento de roteiros para todo o território nacional. No Quadro 1, descreve-se cada um dos roteiros - sua descrição, seus princípios e visão.

Quadro 1. Destinos selecionados para a segunda edição do Projeto Rede de Cooperação Técnica para Roteirização

Macrorregião/Roteiro: Norte Rota 174: Manaus, Presidente Figueiredo, Vila Balbina, Boa Vista, Caracaraí, Pacaraima, Amajari, Rorainópolis

Descrição: Roteiro de Manaus (AM) até Boa Vista (RR), buscando priorizar as consistentes oportunidades da Amazônia, além de proporcionar, num futuro próximo, a sua internacionalização, com a agregação das Ilhas Margaritas, na Venezuela.
Princípios norteadores/Visão de futuro: Ser reconhecido como um roteiro rodoviário que tem duas fortes características: estar localizado na Amazônia brasileira (berço de biodiversidades e culturas) e percorrer diferentes paisagens desde o rio Amazonas, passando pela floresta densa, até o Monte Roraima.

Macrorregião/Roteiro: Nordeste PE/PB/AL - Civilização do açúcar: Areia, Alagoa Grande, Alagoa Nova, Recife, Serraria, João Pessoa, Bananeiras, Olinda, Ilha de Itamaracá, Igarassu, Goiana, Nazaré da Mata, Vicência, Ipojuca, Maceió, Marechal Deodoro, Pilar, Maragogi, Coruripe, Rio Largo, União dos Palmares.

Descrição: Inspirado na experiência da Rota das Emoções (integração dos estados do Piauí, Maranhão e Ceará, na primeira edição do Projeto), agregando, ainda, a visão de complementaridade e diversificação do consagrado segmento de sol e praia, com evidências de novos produtos (como o turismo rural). Território considerado: Paraíba, Pernambuco e Alagoas.
Princípios norteadores/Visão de futuro: Consolidar-se como destino de referência em turismo histórico, cultural e ambiental na região nordeste, e um dos cinco mais competitivos do Brasil até 2014.

Macrorregião/Roteiro: Centro-Oeste MS/MT - Travessia do Pantanal: Cáceres, Poconé, Corumbá, Ladário, Miranda, Porto Murtinho.

Descrição: Busca a consolidação deste produto por meio da integração dos estados do Mato Grosso e Mato Grosso do Sul, possibilitando a complementaridade da oferta turística da região com produtos já conhecidos, a exemplo da Serra da Bodoquena e a Chapada dos Guimarães.
Princípios norteadores/Visão de futuro: Ser reconhecido como um destino confiável, com biodiversidade acessível na maior planície alagada do planeta. 


\section{Macrorregião/Roteiro: Sudeste MG/RJ/SP/ES - Sudeste Recebe: Queluz, Bananal, Guaratinguetá, Aparecida, Campos do Jordão, São Paulo, Jundiaí, Campinas, Socorro, Holambra, Rio de Janeiro, Armação dos Búzios, Paraty, Angra dos Reis, Itatiaia, Valença, Cabo Frio, Petrópolis, Belo Horizonte, Ouro Preto, Tiradentes, São Lourenço, Santana dos Montes, Santa Bárbara, Camanducaia, Monte Verde, Alto Caparaó, Vitória, Guarapari, Venda Nova do Imigrante, Domingos Martins.}

Descrição: Roteiro integrado que envolve todos os quatro estados da região sudeste, possibilitando alternativas viáveis para o desenvolvimento do Cruzeiro Rodoviário, modal e vetor inovador da operação turística.

\section{Princípios norteadores/Visão de futuro:} Pretende ser um destino consolidado, com produtos turísticos diversificados e integrados que valorizem a cultura e a natureza, promovendo a experimentação e a vivência do turista nas localidades, assim como sua autonomia na escolha do roteiro, visando ao desenvolvimento.

Macrorregião/Roteiro: Sul RS/SC - Aparados da Serra: São Joaquim, Urubici, Bom Jardim da Serra, Praia Grande, São José dos Ausentes, Cambará do Sul, São Francisco de Paula.

Descrição: Integra-se com outro roteiro, a Rota dos Tropeiros, permitindo a inclusão do estado do Paraná.

\section{Princípios norteadores/Visão de futuro:}

Consolidar-se como destino turístico de referência na região sul do País até 2014, com os atores integrados e comprometidos com a sustentabilidade, destacando-se os cânions como identidade principal.

Fonte: Elaboração própria com base no Manual da Rede de Cooperação Técnica para a Roteirização (2. ed.) - Tecendo um novo Brasil (BRASIL, 2010).

No processo de estruturação dos roteiros descritos, destaca-se a inserção do desenvolvimento da produção associada ao turismo ${ }^{3}$ como um elemento que agrega valor à oferta turística e promove a construção de um diferencial competitivo nos destinos. Considera-se que a produção associada é um elemento fundamental para que o turista perceba os valores e a identidade dos roteiros, o que possibilita uma experiência mais profunda com a cultura e o contexto sócio-histórico dos destinos.

3 "Produção associada ao turismo é qualquer produção artesanal, industrial ou agropecuária que detenha atributos naturais e/ou culturais de uma determinada localidade ou região, capaz de agregar valor ao produto turístico" (BRASIL, 2010, p. 4). 


\section{O Roteiro Integrado da Civilização do Açúcar em Alagoas}

No início do século XVI, d. João III dividiu o Brasil em capitanias hereditárias e Alagoas - com Paraíba, Rio Grande do Norte, Ceará e parte ocidental da Bahia - incluiu-se na capitania de Pernambuco. O donatário da Capitania - Duarte Coelho - veio com toda a família para o Brasil e implantou os primeiros engenhos de cana-de-açúcar. Assim, a história do estado de Alagoas está intimamente imbricada com a do açúcar que permeia as relações de trabalho, entre familiares e de moradia, constituindo todo um sistema sociopolítico e econômico.

Por meio do Roteiro, no turismo, busca-se traduzir as complexas relações engendradas pela cana-de-açúcar, na casa-grande e na senzala, em belezas e encantamentos a serem ofertados como produtos turísticos na região. Conforme descrição no catálogo promocional produzido pelo Ministério do Turismo para a divulgação do Roteiro, é possível observar:

A história de Alagoas é singular. Os engenhos banguês, que permearam a cultura canavieira durante quatro séculos, evoluíram e se transformaram nas modernas usinas de açúcar que hoje convidam você para uma visitação. Os folguedos e o artesanato diferenciado, como a renda filé, heranças culturais do Brasil Colônia, podem ser vivenciados pelos visitantes em diversas localidades deste estado. A rica gastronomia, baseada em frutos do mar e servida às margens da infinidade de lagoas que dão nome ao estado, é um convite permanente ao deleite. As belas praias reforçam o convite à visitação. Piscinas naturais, peixes que comem em suas mãos e águas límpidas e mornas reforçam a inesquecível experiência de passear pela terra das lagoas (BRASIL, 2008).

No catálogo promocional do RICA, há um convite a experiências encantadoras advindas de uma civilização do açúcar e, assim como todo o processo de planejamento e desenvolvimento do Roteiro, ignoram-se os custos socioambientais dessa cultura. O RICA, em Alagoas, desenvolve-se em um espaço cuja base histórica levou à construção de um modelo centralizador e arcaico de 
desenvolvimento econômico consolidado nos engenhos de açúcar, o que deixou sequelas difíceis de reverter na sociedade alagoana.

A forma como o cultivo da cana se desenvolveu no decurso da história causou sérios danos ambientais, como a devastação desmedida da mata atlântica, a destruição da matéria orgânica do solo em decorrência de queimadas para sua limpeza, gerando erosões, o que ainda vem provocando assoreamento em mananciais, além de eliminação de micro-organismos do solo.

Além de um histórico de degradação ambiental, a sociedade canavieira, em seu princípio escravista, tem uma história de opressão, sofrimento, dominação, patriarcalismo, despotismo, exclusão social e violência. Como resultado, pode-se afirmar, com base nas palavras de Carvalho (2013), que a herança do período açucareiro assim se traduz:

[...] um frágil processo de industrialização, uma urbanização gerada não pela atração das oportunidades nas pequenas e médias cidades, mas pela inviabilização da vida do homem do campo, indicadores de desenvolvimento humano comparáveis às regiões mais subdesenvolvidas do planeta e um atraso político que gravou, no imaginário nacional, o estado de Alagoas como a pátria de todos os desmandos.

O estado de Alagoas apresenta uma população de 3.120.494 (IBGE, 2010) e uma área de $27.778 .506 \mathrm{~km}^{2}$. Sua história é marcada pela extrema concentração de renda e poder nas mãos de algumas famílias. Segundo Lira (2007), cerca de $80 \%$ dos investimentos feitos no estado provêm do governo federal - os principais beneficiados são os "senhores da cana-de-açúcar" - e apenas 18 famílias de usineiros dominam 65\% do PIB de Alagoas. Trata-se do segundo estado brasileiro com maior Índice de Gini $(0,47)^{4}$ no País, o que aponta

\footnotetext{
${ }^{4}$ O Índice de Gini mede o grau de desigualdade existente na distribuição de indivíduos segundo a renda domiciliar per capita. Seu valor varia de 0 , quando não há desigualdade (a renda de todos os indivíduos tem o mesmo valor), a 1, quando a desigualdade é máxima (apenas um indivíduo detém toda a renda da sociedade e a renda de todos os outros indivíduos é nula).
} 
para uma concentração de renda nas mãos de uma minoria, ou para uma significativa diferença entre rendimentos dos mais pobres e dos mais ricos.

Está entre os piores Índices de Desenvolvimento Humano - IDHs - do País $(0,63)$, liderando as taxas de mortalidade infantil, e 46,4 a cada mil crianças nascidas vivas, morrem antes de completarem um ano de vida, o que significa mais que o dobro da média nacional, que é de 22 (IBGE, 2010). Trata-se da unidade da federação com a pior taxa de analfabetismo - 24,6\% de analfabetos e $36,5 \%$ de analfabetos funcionais - e onde apenas $20 \%$ das residências são atendidas por redes de esgoto, caracterizando a deficiência do saneamento básico (ALAGOAS, 2013).

Em 2008, início do processo de planejamento do RICA, 22,24\% da população apresentavam-se sem rendimento algum, e 47,09 recebiam até um salário mínimo. No mesmo período, 345.516 famílias eram atendidas pelo Programa Bolsa Família do governo federal. Assim, sabendo-se que se estimam, em cada família, quatro pessoas, calcula-se que 1.380 .064 pessoas eram diretamente beneficiadas pelo Programa, ou seja, aproximadamente, $44 \%$ da população alagoana (IPEADATA, 2010).

Em Alagoas, o turismo é o principal componente do setor de serviços, além de ser a segunda atividade que mais cresce no estado perdendo apenas para a indústria sucroalcooleira. Mas, embora o turismo represente uma atividade econômica em processo de desenvolvimento, o modelo vigente tem gerado uma conjuntura de absoluta exclusão da população local nesse processo, como apontam Vasconcelos e Bezerra (2012, p. 153).

A consequência deste processo tem sido um aprofundamento das desigualdades sociais através da má distribuição de renda, na medida em que o turismo de massa reforça a concentração do capital nas posses de uma minoria. $\mathrm{Na}$ prática, diante da ausência de outras práticas turísticas alternativas ao modelo dominante, como o turismo de massa, os lucros e dividendos dos empreendimentos turísticos vão ser repartidos e concentrados entre os proprietários da rede hoteleira, das agências 
de viagens e do complexo circuito que se desenvolve ao redor do trade turístico local: os donos dos grandes restaurantes, dos hotéis, das empresas de receptivo, etc.

Assim, a política atual de turismo insere-se em Alagoas como uma espécie de salvação para os problemas sociais apresentados e como um desafio de envolver a população em uma atividade econômica concentrada, a princípio, em função do modelo vigente, em grandes redes hoteleiras, operadoras e serviços de alimentação; mas fato é que o processo de planejamento parece ignorar as estruturas de poder consolidadas no local, tanto a instaurada no século XVI, quanto a assentada no modelo dominante de turismo, o que compromete o processo de consolidação de objetivos e metas estabelecidos pelo próprio programa político.

\section{Dificuldades para a consolidação do Roteiro Integrado da Civilização do Açúcar no estado de Alagoas}

No Roteiro Integrado da Civilização do Açúcar, objetivava-se consolidar como destino de referência em turismo histórico-cultural e ambiental na região nordeste, e ser um dos cinco roteiros mais competitivos do Brasil até 2014 (BRASIL, 2010); mas o processo de desenvolvimento atravessou uma série de problemas, o que inviabilizou sua consolidação como produto. Atualmente, o Roteiro é parcialmente operacionalizado no estado de Pernambuco, mas não é exequível na Paraíba e em Alagoas. Na verdade, trata-se de um produto que não se firmou no mercado e é, portanto, um projeto fracassado, uma vez que os objetivos da roteirização, ou seja, integrar estados e regiões em torno da proposta do desenvolvimento sustentável da atividade econômica do turismo, não se concretizaram.

Para entender os possíveis motivos que conduziram ao fracasso do Roteiro, fez-se uma análise documental dos programas políticos e dos manuais 
elaborados pelo SEBRAE, MTur e IMB, a fim de compreender as metodologias utilizadas e as etapas de planejamento. A pesquisa constituiu-se em um estudo de caso, concentrando-se na análise dos motivos que se tornaram empecilhos para a consolidação do Roteiro no estado de Alagoas. Realizaram-se visitas técnicas aos municípios alagoanos do Roteiro e entrevistas com gestores públicos municipais das secretarias de turismo dos municípios envolvidos (Maceió, Coruripe, Maragogi e União dos Palmares). Pautaram-se as entrevistas em avaliar, na visão dos gestores entrevistados, o processo de desenvolvimento das etapas de planejamento propostas pela metodologia utilizada para a implantação do RICA, etapas descritas no Quadro 2, síntese do que consta no Manual de Orientações Metodológicas da Rede de Cooperação Técnica para a Roteirização.

Quadro 2. Metodologia utilizada na Roteirização/Rede de Cooperação Técnica para a Roteirização

\begin{tabular}{|c|c|c|}
\hline Etapas & Descrição & Desafios \\
\hline $\begin{array}{l}\text { Definição dos } \\
\text { territórios envolvidos }\end{array}$ & $\begin{array}{l}\text { Definição do recorte } \\
\text { territorial e da } \\
\text { identidade do roteiro } \\
\text { integrado proposto }\end{array}$ & $\begin{array}{l}\text { - Identificar localidades com } \\
\text { identidade comum/identidade } \\
\text { coletiva do Roteiro; intervenções } \\
\text { políticas no processo de escolha. } \\
\text { - Acesso entre as localidades } \\
\text { escolhidas e estruturas de } \\
\text { deslocamento existentes. } \\
\text { - Abertura do território para o } \\
\text { trabalho articulado entre estados e } \\
\text { roteiros turísticos, em diferentes } \\
\text { níveis de consolidação no mercado. }\end{array}$ \\
\hline $\begin{array}{l}\text { Instalação do comitê } \\
\text { gestor do Roteiro }\end{array}$ & $\begin{array}{l}\text { Formação de um grupo } \\
\text { de pessoas responsável } \\
\text { pela gestão do destino } \\
\text { turístico integrado, } \\
\text { associando os } \\
\text { interesses da iniciativa } \\
\text { privada em todos os } \\
\text { setores da atividade } \\
\text { turística, do Poder } \\
\text { Público e das } \\
\text { comunidades. }\end{array}$ & 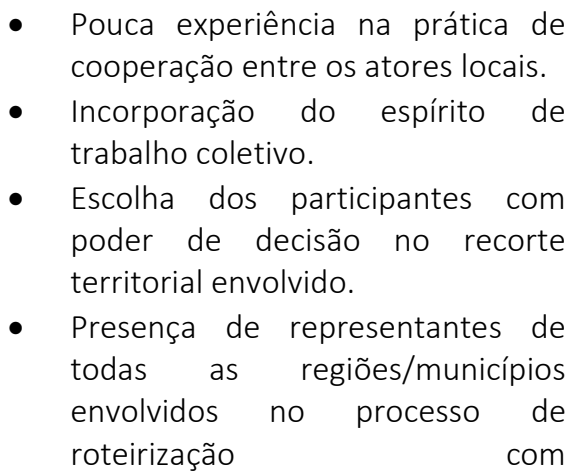 \\
\hline
\end{tabular}




\begin{tabular}{|c|c|c|}
\hline & & $\begin{array}{l}\text { representatividade equilibrada do } \\
\text { setor público e da iniciativa privada. } \\
\text { Dependência dos consultores para } \\
\text { dinamizar a rede de cooperação } \\
\text { entre os integrantes do comitê } \\
\text { gestor. } \\
\text { - Distância territorial do Roteiro } \\
\text { dificultando os encontros } \\
\text { presenciais. } \\
\text { Pouca compreensão da importância } \\
\text { da sistematização das informações } \\
\text { em um banco de dados. }\end{array}$ \\
\hline $\begin{array}{l}\text { Realização do } \\
\text { diagnóstico do Roteiro }\end{array}$ & $\begin{array}{l}\text { Levantamento e análise } \\
\text { de dados referentes ao } \\
\text { território envolvido, a } \\
\text { fim de oferecer } \\
\text { subsídios ao grupo de } \\
\text { trabalho para a } \\
\text { elaboração do } \\
\text { planejamento } \\
\text { estratégico. }\end{array}$ & $\begin{array}{l}\text { - } \text { Envolvimento efetivo do comitê } \\
\text { gestor na busca de informações. } \\
\text { - } \text { Acesso a informações. } \\
\text { - } \text { Resistência por parte do comitê } \\
\text { gestor e dos consultores de Roteiro } \\
\text { em hierarquizar os atrativos e } \\
\text { definir os segmentos-âncora. } \\
\text { - Dificuldade de compreensão da } \\
\text { importância de segmentar o } \\
\text { mercado, buscando analisar o nível } \\
\text { de atratividade em diferentes } \\
\text { segmentos. } \\
\text { Analisar possíveis impactos } \\
\text { socioculturais e ambientais. }\end{array}$ \\
\hline $\begin{array}{l}\text { Construção do } \\
\text { planejamento } \\
\text { estratégico }\end{array}$ & $\begin{array}{l}\text { Elaboração de um } \\
\text { planejamento } \\
\text { estratégico com base } \\
\text { na análise situacional } \\
\text { do território com } \\
\text { definições de ações } \\
\text { que terão influência } \\
\text { sobre o processo de } \\
\text { roteirização. }\end{array}$ & $\begin{array}{l}\text { - As regiões entraram nesta fase sem } \\
\text { a conclusão do diagnóstico, } \\
\text { dificultando o fechamento } \\
\text { consistente do planejamento no } \\
\text { tempo desejado. } \\
\text { - } \text { Respeito a diferenças e } \\
\text { peculiaridades de cada Roteiro, } \\
\text { permitindo que cada um possa } \\
\text { conceber seu plano estratégico. } \\
\text { Elaboração do planejamento de } \\
\text { forma participativa pela instância } \\
\text { de governança do Roteiro por meio } \\
\text { das oficinas de planejamento. }\end{array}$ \\
\hline $\begin{array}{l}\text { Implantação do plano } \\
\text { operacional }\end{array}$ & $\begin{array}{l}\text { Implementação das } \\
\text { ações estabelecidas no } \\
\text { plano estratégico, com } \\
\text { foco mercadológico. }\end{array}$ & 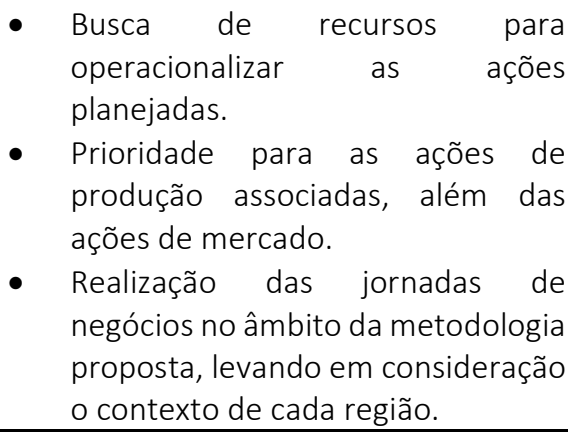 \\
\hline
\end{tabular}




\begin{tabular}{|c|c|c|}
\hline & & $\begin{array}{l}\text { - Lançamento do Roteiro conforme } \\
\text { - } \text { Retas do Projeto. } \\
\text { envolização de ações de mercado, } \\
\text { de comercialização. }\end{array}$ \\
\hline $\begin{array}{l}\text { Acompanhamento e } \\
\text { avaliação das ações } \\
\text { implantadas }\end{array}$ & $\begin{array}{l}\text { Monitoramento das } \\
\text { ações realizadas, de } \\
\text { acordo com o plano de } \\
\text { ações estabelecido } \\
\text { pelo grupo. }\end{array}$ & 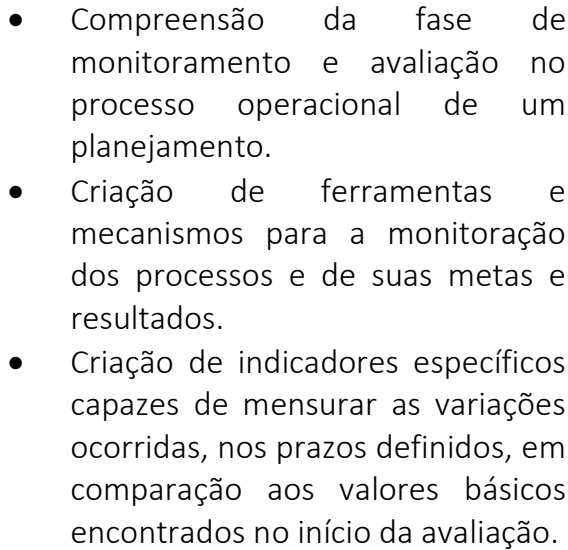 \\
\hline
\end{tabular}

Fonte: Elaboração própria, com base no Manual de Orientações Metodológicas da Rede de Cooperação Técnica para a Roteirização (IMB, 2008).

No que se refere à primeira etapa "Definição dos territórios envolvidos" é importante observar que o potencial turístico dos municípios para o turismo cultural e a identidade comum, o compartilhamento de uma história e a presença dos engenhos de cana-de-açúcar e todo um patrimônio cultural que permeia a cultura são atributos que se destacam na área definida, tornando-a promissora para um trabalho com a estruturação de roteiros culturais, que permitem ainda a constituição de um produto voltado também para o turismo de sol e praia, turismo de aventura e turismo ecológico, como segmentos complementares.

Por outro lado, a seleção dos municípios, que deveriam compor o RICA, deveria obedecer a determinados critérios que foram desconsiderados no estado de Alagoas. Os gestores entrevistados apontam que havia muito interesse em inserir o município no RICA, principalmente pela visibilidade que isso traria ao município no cenário nacional e que fomentar o turismo nas referidas localidades era elemento central em todas as plataformas políticas, mas a maioria dos atrativos não apresentava condições de ser explorada e, nos municípios, carecia-se de equipamentos turísticos essenciais, como hotéis, 
pousadas e restaurantes, com padrões adequados de qualidade para atender ao turista.

O patrimônio cultural, como monumentos, igrejas e os próprios engenhos de cana-de-açúcar, encontrava-se sem condições mínimas para a promoção de visitas, demandando reformas estruturais e obras de restauração. Nos territórios envolvidos, havia matéria-prima para construírem-se produtos, mas os atrativos não estavam preparados e talvez não tivessem condições e nem recursos para se prepararem no prazo proposto pelas metas do Roteiro.

Não se levou em consideração a maturidade da gestão pública de turismo dos municípios para trabalhar na elaboração de um itinerário cultural. Os gestores relataram a dificuldade de trabalhar com o desenvolvimento de produtos turísticos para um turista de motivações culturais que apresenta demandas bem diferenciadas das de um turista de "sol e mar". Vale lembrar que o itinerário cultural é um meio de expressão, é o propósito de explicar algo a alguém, um processo de comunicação que se estrutura com base em leitura interpretativa da realidade. No caso do RICA, não se trata apenas de realizar um mapeamento de atrativos culturais, mas de construir elementos que permitam narrativas e interpretações de modos, costumes, saberes e fazeres (RAMOS; SANTOS, 2011).

Diante da proposta do RICA, seria insuficiente um trabalho de melhoria do aspecto físico dos atrativos, pois o produto demandava capacidade técnica dos profissionais de planejamento para trabalhar com as peculiaridades do desenvolvimento do turismo de experiência ${ }^{5}$ por meio de amplas pesquisas -

\footnotetext{
5 É necessário entender que o turista, hoje, tem expectativas que vão além da contemplação passiva dos atrativos. Esse novo perfil de turista, ativo e criativo, quer realizar um desejo além de se sentir um ator importante na construção do destino visitado. Tal turista, que está cada vez mais autônomo e bem-informado, busca envolver parentes e amigos nesse processo, fazendo com que a viagem não seja somente lazer, mas também uma atitude militante de partilhar o ambiente, a comunidade visitada e a cultura local, vivendo experiências inesquecíveis e obtendo o poder de convencer os próximos a tomarem essa atitude: viajar com inteligência (BRASIL, 2011).
} 
entre elas, um inventário de referências culturais dos municípios. Os gestores municipais relatam que não se sentiam em condições nem mesmo de fazer o inventário turístico nos moldes propostos pelo Ministério do Turismo e incapazes de pensar em um inventário ainda mais complexo, como o demandado para o desenvolvimento do referido produto, com todas as suas especificidades.

A segunda etapa - "Instalação do comitê gestor" - é considerada a principal, de acordo com os princípios do programa político. O grupo gestor é definido como um grupo de pessoas responsáveis pela gestão do destino turístico integrado, associando-se os interesses da iniciativa privada em todos os setores da atividade turística, do Poder Público e das comunidades locais que têm um papel central no processo de planejamento e desenvolvimento do Roteiro e constituem a estrutura do planejamento participativo, garantindo a representatividade de todos os setores no processo (IMB, 2008). O principal foco desse grupo é trabalhar para que o destino turístico integrado seja reconhecido pelo mercado-alvo, unindo a natureza e a diversidade cultural com foco nos princípios da sustentabilidade.

Segundo o Manual de Orientações Metodológicas da Rede de Cooperação Técnica (IMB, 2008, p. 25), o grupo gestor apresenta como papel:

Tornar o processo participativo; ser porta-voz do comitê com as comunidades e o governo; ser o "arquiteto" do destino turístico, direcionando o plano operacional de acordo com o plano estratégico traçado; promover o sincronismo das ações em todo o território; coordenar ações pensadas regionalmente, mas operacionalizadas localmente; alimentar constantemente o banco de informações do Roteiro; buscar, de forma mais eficiente, recursos para incrementar o destino integrado.

Pelo papel atribuído ao referido grupo, delega-se a ele a capacidade e a autonomia para tomar decisões e desenvolver todo o processo de planejamento, tendo como base os princípios da representatividade dos três setores (iniciativa privada, setor público e comunidade local). Porém, na prática, os próprios 
gestores municipais de turismo revelam que seus papéis se limitam a regulamentar determinadas ações e que o processo de desenvolvimento do turismo se concentra nas mãos de uma elite do empresariado, tanto que todos os gestores entrevistados apontam a desorganização e a dificuldade de mobilização e de engajamento dos pequenos empreendedores como as principais causas do fracasso do RICA. Percebe-se que o Poder Público é visto como mero coadjuvante no processo e, dessa forma, sua representatividade no grupo fica comprometida, contradizendo a própria proposta da Rede de Cooperação Técnica.

A atitude do Poder Público no grupo gestor conduz à reflexão sobre o papel do Estado no desenvolvimento do turismo e traz à cena a problemática da gestão participativa e da necessidade de analisar a forma como o referido canal de participação se efetiva, tendo em vista as estruturas de poder, a multiplicidade de interesses e os conflitos locais.

Observa-se que o princípio de que o estado deve representar os interesses gerais e não os de grupos específicos, como as elites locais, em prol de conduzir as decisões de forma a que atendam a interesses próprios e não às necessidades de uma comunidade mais ampla (HALL, 2004), é negligenciado em Alagoas. O fato de o Poder Público atribuir poder e autonomia à iniciativa privada acaba facilitando a consolidação de interesses de grupos que já dominam os territórios no turismo e promovem o modelo turístico atual que é o de sol e mar.

Os indicadores sociais do estado de Alagoas, como a alta taxa de analfabetismo, de mortalidade infantil, de desemprego e de pobreza, evidenciam a exclusão social da população, fato que se relaciona diretamente com o processo de exclusão política (GIDDENS, 2005), e, certamente, faltam à população informações e condições mínimas de repertório para compreender o que significa o desenvolvimento do turismo nos municípios, como é possível beneficiar-se desse processo e a importância de participar ativamente do 
planejamento. Nesse sentido, Silveira (2002, p. 96-97) discute o fenômeno da participação na gestão do turismo e suas formas, e caracteriza

\begin{abstract}
a distinção entre participação ampla em todos os estágios do processo de planejamento, implementação e controle de ações de desenvolvimento, e a simples manipulação de recursos humanos para implementação de projetos, programas ou planos turísticos concebidos de fora e impostos à população de forma mais ou menos autoritária.
\end{abstract}

Sabe-se que, na realidade alagoana, vive-se um cotidiano de práticas clientelistas e veem-se os próprios direitos do cidadão como favores e concepções especiais do estado que, muitas vezes, são negociados como moedas de troca. A voz da população local acaba sendo utilizada apenas como um processo de legitimação das ações de determinados grupos de interesse que detêm o poder; o suposto canal de participação se transforma em uma nova estrutura de dominação e recebe uma nova roupagem, que, muitas vezes, engana olhares menos apurados, configurando uma aparência de gestão participativa.

Dessa forma, com o desequilíbrio de poder entre as três esferas, o elemento representatividade fica absolutamente comprometido e não há como se consolidar um grupo gestor para o Roteiro que possa garantir o desenvolvimento de um turismo sustentável.

$\mathrm{Na}$ terceira etapa, "Realização do diagnóstico do Roteiro", três consultores (de Mercado, de Produção Associada e de Turismo) da Rede de Cooperação Técnica para a Roteirização, por meio de visitas técnicas, executaram pesquisas de mercado, entrevistas com operadoras, pesquisas de demanda e oferta, o que se constituiu em um amplo trabalho em que se avaliaram impactos do turismo nos âmbitos socioambiental, cultural e econômico, caracterizando, dessa forma, a dinâmica territorial local. O diagnóstico se constituiu em um documento em que se avaliaram as características do território envolvido, as tendências para o mercado turístico 
real e potencial, e a constituição do produto turístico. Fez-se uma análise do processo de promoção, distribuição e comercialização, promoveram-se a hierarquização dos atrativos e a definição dos segmentos âncoras e construiu-se uma matriz de pontos fortes e fracos, que são as informações necessárias para elaborar planos de ação (FREIRE et al., 2007).

O diagnóstico foi concebido para ser utilizado como ferramenta educativa e disseminadora de informações relevantes relativas ao local estudado, como forma de conscientização sobre as características do ambiente, para empreendedores que desejam obter informações suficientes para o processo decisório (FREIRE et al., 2007, p. 6).

Por outro lado, esse instrumento central no processo de planejamento foi apresentado para o grupo gestor e ameaças e debilidades identificadas não foram levadas em consideração e trabalhadas pelo grupo. Segundo os gestores públicos entrevistados, o grupo gestor não se debruçou sobre ele como um documento essencial para a construção de um planejamento do RICA em Alagoas, ou seja, o diagnóstico foi absolutamente subestimado, o que inviabilizou toda a metodologia proposta para a estruturação do Roteiro.

As etapas "Construção do planejamento estratégico" e "Implantação do plano operacional" ficaram totalmente comprometidas, uma vez que eram dependentes do diagnóstico e do desempenho do grupo gestor no processo de planejamento. Os gestores indicaram a dificuldade de planejar um cenário futuro para os municípios alagoanos, apontando um histórico de descrença nos projetos políticos decorrentes da prática da descontinuidade das ações propostas. Há, pois, uma dificuldade significativa de projetar o futuro para uma sociedade como a alagoana em que grupos adversários se revezam no poder e, ao fim de cada gestão, liquidam os projetos anteriores. Os gestores afirmam que, quando assumem as secretarias municipais, sempre têm de "começar do zero" porque 
os projetos, vistos como plataformas políticas, são destruídos ao final de cada gestão.

Como parte do plano operacional, fez-se a divulgação no Salão de Turismo6, simultaneamente em 2009, 2010 e 2011, com um amplo trabalho promocional e a produção de catálogos folders e de um CD do Roteiro. Segundo os gestores, divulgou-se uma proposta e não um produto, porque efetivamente o RICA, em Alagoas, não era operacionalizado. No Roteiro, projetou-se uma imagem de Alagoas, no cenário nacional, que não condizia com o cenário real.

O "Acompanhamento e avaliação das ações implantadas", sexta etapa da metodologia para o desenvolvimento dos roteiros, não foi contemplada no processo de desenvolvimento do RICA. Ressalte-se que a avaliação é um elemento fundamental no planejamento porque permite rever os erros e redirecionar as estratégias. Seria, dessa forma, muito importante avaliar o processo para rever as falhas - principalmente para não repeti-las. Entretanto não houve organização e mobilização do grupo gestor do RICA em Alagoas para que um processo avaliativo se efetivasse.

Outros elementos são apontados pelos gestores públicos como motivadores das falhas na consolidação do Roteiro em Alagoas. Entre eles, a falta de sensibilização do trade turístico, a dificuldade de compreensão da importância da necessidade de melhoria de condições de vida da população local para o próprio desenvolvimento do turismo, a falta de visão de mercado dos empreendedores locais para a necessidade da segmentação e a consideração de um novo turista com uma demanda diferenciada. Nos discursos dos gestores públicos municipais, o trade turístico de Alagoas foi caracterizado como

\footnotetext{
${ }^{6}$ O Salão do Turismo foi uma estratégia de mobilização, promoção e comercialização dos roteiros turísticos desenvolvidos com base nas diretrizes do Programa de Regionalização do Turismo - Roteiros do Brasil, promovido pelo governo federal por meio do Ministério do Turismo (BRASIL, 2012a).
} 
acomodado com a estrutura de sol e mar e suas facilidades, conservador, despreparado e resistente a mudanças.

Resta indagar por que, no trade turístico - em franco processo de desenvolvimento, com a demanda pelo turismo de sol e mar crescendo a cada ano -, é importante um trabalho para a consolidação de outro modelo de turismo que demanda mão de obra qualificada, que tenha habilidades diferenciadas para trabalhar com a exploração do patrimônio cultural, além de toda uma infraestrutura peculiar a roteiros temáticos? Vasconcelos e Bezerra (2012, p.154) diante do contexto atual do turismo em Alagoas também se perguntam:

Se um modelo está dando certo, quais razões existiriam para se procurar outro? É esta a questão que se articula a partir do segmento das elites alagoanas envolvidas com o somatório dos interesses do turismo local. Afinal, se nas altas temporadas a rede hoteleira está com a sua capacidade lotada, quais razões haveria para mudanças? Por que haveria de existir uma alternativa governamental ao modelo existente?

Para responder a tantos questionamentos, os autores se remetem ao que denominam "fortalecimento da rede de conveniências e seu agenciamento":

[...] o trade turístico indica seus representantes no setor público vinculado ao turismo do estado, o qual por sua vez escolhe seus quadros técnicos viciados na eficácia do mesmo paradigma, o que, na prática, implica fortalecimento do atual modelo, perpetrando assim a permanência do atual círculo vicioso de sol e mar (VASCONCELOS; BEZERRA, 2012, p. 155).

Como se pode observar, há uma estratégia de gestão, que veste a roupagem de gestão participativa e que garante a perpetuação do modelo atual de turismo de sol e mar, gerando o fracasso do Roteiro Integrado da Civilização do Açúcar, em Alagoas. Nas políticas federais de turismo, ignoram-se, completamente, os conflitos ao conceber os espaços como harmônicos, 
integrados e sinérgicos, além de desconhecer os resultados e custos sociais e ambientais do período histórico que tematiza o Roteiro em questão.

O planejamento do turismo, seja ele numa escala regional ou local, não se dá sobre um espaço "plano" e "vazio", um receptáculo puro e simples de nossas ações. Ao contrário, este planejamento se dá sobre um espaço concreto, herdado, histórica e socialmente construído e que, portanto, tem de ser considerado pela política pública e pelos programas e projetos que dela derivam (CRUZ, 2005, p. 40).

Pela análise do RICA, em Alagoas, surge uma reflexão sobre o planejamento e a gestão participativa e, principalmente, sobre as estratégias que estão sendo utilizadas para o desenvolvimento dos programas políticos. 


\section{Considerações finais}

O despreparo das municipalidades, a situação dos atrativos e equipamentos turísticos, a falha nos critérios de seleção dos mesmos para compor o Roteiro, a falta de habilidade para trabalhar os elementos apontados pelo diagnóstico e desenvolver um planejamento estratégico, com base em ameaças e debilidades identificadas no cenário, a falta de condições da população local, sua exclusão política e dificuldades de participar efetivamente nos processos de decisão e a limitação do papel do estado são elementos bastante significativos apontados como motivadores do fracasso do RICA no estado de Alagoas.

Por outro lado, destaca-se, como principal elemento, a dificuldade de consolidação de um grupo gestor devidamente equilibrado com a representatividade de cada um dos três setores e que cumpra seu papel conforme determinação do programa político.

Por meio da análise do processo de planejamento e desenvolvimento do RICA em Alagoas, foi possível identificar que, em razão das políticas federais de turismo, reduz-se o espaço turístico a um "puro e simples receptáculo de suas ações às quais devem somar-se as ações dos agentes de mercado" (CRUZ, 2005). Pela metodologia proposta para o desenvolvimento do RICA, constata-se a ignorância total - ou talvez a negligência proposital dos profissionais de planejamento e gestores das políticas federais de turismo - no que se refere a estruturas de poder vigentes e a características histórico-sociais e culturais da localidade.

No cenário apresentado, coloca-se a necessidade proeminente de estudos e pesquisas que apontem metodologias de planejamento que permitam a construção de um olhar mais apurado sobre as peculiaridades e as configurações do espaço turístico para que, com isso, se consiga abarcar a 
complexidade do fenômeno e permitir condições efetivas para o desenvolvimento dessa atividade econômica para além do modelo de sol e mar.

\section{Referências}

ALAGOAS. Secretaria do Estado do Planejamento e do Desenvolvimento Econômico (SEPLANDE). Alagoas em dados e informações, 2013. Disponível em: http://informacao.seplande.al.gov.br/. Acesso em: 4 abr.2013.

BRASIL. Ministério do Desenvolvimento Social e Combate à Fome. Bolsa Família, 2013. Disponível em: http://www.mds.gov.br/bolsafamilia. Acesso em: 12 abr. 2013.

BRASIL. Ministério do Turismo. Economia da Experiência, 2011. Disponível em: http://www.turismo.gov.br/turismo/programas acoes/regionalizacao turismo/economia experiencia.htm. Acesso em: 11 nov. 2012.

Plano Nacional de Turismo: Diretrizes, Metas e Programas - 2003 /2007. Brasília: Ministério do Turismo, 2003.

Programa de Regionalização do Turismo - Roteiros do Brasil. Brasília: Ministério do Turismo, 2004.

Programa de Regionalização do Turismo - Roteiros do Brasil — Produção e Apoio à Comercialização. Brasília: Ministério do Turismo, 2007 a.

Programa de Qualificação a Distância para o Desenvolvimento do Turismo: Turismo e Sustentabilidade - Formação de Redes e Ação Municipal para Regionalização do Turismo. Florianópolis: SEAD/UFSC, 2008 a.

Rede de Cooperação Técnica para a Roteirização - Tecendo um Novo Brasil. 2. ed. Brasília: SEBRAE, MTUR/IMB, 2010.

Roteiro Integrado da Civilização do Açúcar. Brasília: SEBRAE, 2008. (Catálogo)

Salão de Turismo - Roteiros do Brasil, 2012a. Disponível em: http://www.turismo.gov.br/salao/sobre evento/principal/. Acesso em: 24 fev. 2012.

Turismo cultural, 2012. Disponível em: http://www.turismo.gov.br/turismo/programas_acoes/regionalizacao_turismo/estruturac ao segmentos/turismo cultural.html. Acesso em: 14 nov. 2012.

_

CARVALHO, C.P. Os ciclos históricos de uma economia dependente - Parte I, 2013. Associação Brasileira para o Desenvolvimento das Lideranças. Disponível em: http://www.abdl.org.br/filemanager/download/119/EconomiaDependente CiceroCarvalh o PronordT1S3.doc. Acesso em: 12 abr. 2013. 
CRUZ, R. Políticas públicas de Turismo no Brasil: território usado, território negligenciado. Revista Geosul. Universidade Federal de Santa Catarina, vol. 20, n.o 40, p. 28-43, 2005.

FREIRE, A. et al. Rede de Cooperação Técnica para Roteirização - Termo de parceria MTUR/IMB/n.o 011. Brasília: SEBRAE, MTUR/IMB, 2007.

GIDDENS, A. Pobreza, previdência social e exclusão social. In:

Sociologia. 4. ed. Porto Alegre: ARTMED, 2005, p. 254-281.

GONÇALVES, M. A. S. Estudo de caso: reflexões sobre paradigmas. Unirevista, Porto Alegre, $n .^{\circ} 1$, p. 19-22, 2006.

HALL, C. M. Planejamento turístico: políticas, processos e relacionamentos. São Paulo: Contexto, 2004.

IBGE. Instituto Brasileiro de Geografia e Estatística (2010). Censo 2010. Disponível em: http://www.censo2010.ibge.gov.br/resultados do censo2010.php Acesso em: 20 nov. 2010

IMB. Instituto Marca Brasil. Manual de Orientações Metodológicas - Rede de Cooperação Técnica para a Roteirização. 2. ed. Brasília: SEBRAE, MTUR, IMB, 2008.

IPEADATA. Dados sociais: Renda. 2011. Disponível em: http://www.ipeadata.gov.br/ipeaweb.dll/ipeadata?SessionID=1972569292\&Tick=1277503 770364\&VAR FUNCAO=Ser Temas\%281413839281\%29\&Mod=S. Acesso em: 8 mar. 2012

LIRA, F. J. Formação da riqueza e da pobreza de Alagoas. Maceió, AL: Edufal, 2007.

RAMOS, S.P.; SANTOS, A.M. Traçando itinerários culturais para um turismo de experiência: o caso do Caminho Lagunar-AL. In: RAMOS, S.P. (org.) Planejamento de roteiros turísticos. Porto Alegre: Asterisco, p.11-36, 2012.

SILVEIRA, M. A. Planejamento territorial de dinâmica local. In RODRIGUES, A. Turismo e desenvolvimento local. São Paulo: Hucitec, p.91-10, 2002

SLEE, B. Theoretical Aspects of the Study of Endogenous Development. In: PIOEG, J. D. van der; LONG, A. (eds,) Born from Within: Practice and Perspectives of Endogenous Rural Development. Van Gorcum, Assen: The Netherlands, 1994.

VASCONCELOS. D.A.; BEZERRA, E. Reflexões sobre modernidade, turismo e campo social no estado de Alagoas-Brasil. Revista Iberoamericana de Turismo, Penedo-AL, vol. 2, n.o 2, p. 146-158, 2012.

ARGYRIS, C. Teaching smart people how to learn. Harvard Business Review, vol. 69, n. ${ }^{\circ}$ 3, p. 99109, maio/jun. 1991.

BARATO, Jarbas. Educação profissional: saberes do ócio ou saberes do trabalho?. São Paulo: Senac São Paulo, 2005. 


\section{Silvana Pirillo Ramos}

Professora Associada da Universidade Federal de Alagoas (UFAL) no Curso de Turismo Pesquisadora do Conselho Nacional de Desenvolvimento Científico e Tecnológico (CNPQ) Líder do Grupo "Observatório Transdisciplinar de Pesquisas em Turismo" da UFAL Doutora em Sociologia e Mestre em Política pela Pontifícia Universidade Católica de São Paulo (PUC-SP)

silvanapirillo@uol.com.br Av. Divaldo Suruagy, s./n. CEP: 57200-000 - Penedo-Alagoas (Brasil)

\section{Levy Felix Ribeiro}

Pós-graduando em Políticas Públicas e Planejamento Governamental - Centro Universitário Tiradentes (Unit)

Bacharel em Turismo pela Universidade Federal de Alagoas (UFAL) levyfelixtur@gmail.com

Av. Comendador Gustavo Paiva, 5017 - Cruz das Almas, Maceió - AL, 57038-000 